\title{
Resistencia antimicrobiana. Importancia y esfuerzos por
} contenerla

\author{
Silvia Giono-Cerezo, ${ }^{1 *}$ José I. Santos-Preciado, ${ }^{2}$ María del Rayo Morfín-Otero, ${ }^{2}$ \\ Francisco J. Torres-López ${ }^{3}$ y María Dolores Alcántar-Curie/4
}

${ }^{1}$ Instituto Politécnico Nacional, Escuela Nacional de Ciencias Biológicas, Departamento de Microbiología, Ciudad de México; ${ }^{2}$ Universidad de Guadalajara, Hospital Civil de Guadalajara "Fray Antonio Alcalde", Guadalajara, Jalisco; ${ }^{3}$ Instituto Mexicano del Seguro Social, Centro Médico Nacional Siglo XXI, Hospital de Pediatría, Ciudad de México; ${ }^{4}$ Universidad Nacional Autónoma de México, Facultad de Medicina, Unidad en Medicina Experimental, Ciudad de México. México

\section{Resumen}

La Organización Mundial de la Salud estima que en 2050 la resistencia bacteriana ocasionará 10 millones de muertes. Como parte del Plan de Acción Mundial sobre la Resistencia a los Antimicrobianos propuso redes de laboratorios especializados, para conservar cepas y optimizar el uso de los antimicrobianos. En un estudio de 2019 se identificó que las principales bacterias del grupo ESKAPE (con alta resistencia a los antibióticos más usados) que causan infecciones en hospitales de México son Klebsiella spp. resistentes a múltiples fármacos (MDR) y productoras de betalactamasa de espectro extendido (BLEE), Enterobacter spp. BLEE, Acinetobacter baumannii, Pseudomonas aeruginosa MDR, Staphylococcus aureus meticilinorresistente y Enterococcus faecium resistente a vancomicina. Con la información de resistencia a los fármacos se recomiendan esquemas para tratar la infección causada por Helicobacter pylori, relacionado con el desarrollo de cáncer y cuya prevalencia en la población adulta de Latinoamérica se estima es de entre 60 y 70 \%.

PALABRAS CLAVE: Estrategia Nacional. Resistencia antimicrobiana. Grupo ESKAPE. Helicobacter pylori.

\section{Antimicrobial resistance. Its importance and efforts to control it}

\section{Abstract}

The World Health Organization estimates that bacterial resistance will cause 10 million deaths by 2050. As part of the Global Action Plan on Antimicrobial Resistance, it proposed networks of specialized laboratories in order to preserve strains and optimize the use of antimicrobials. In a 2019 study, the main bacteria of the ESKAPE group (which are highly-resistant to the most widely used antibiotics) that cause infections in Mexican hospitals were identified to be multidrug-resistant (MDR) and extended spectrum beta-lactamase (ESBL)-producing Klebsiella spp., ESBL-producing Enterobacter spp., Acinetobacter baumannii, MDR Pseudomonas aeruginosa, methicillin-resistant Staphylococcus aureus and vancomycin-resistant Enterococcus faecium. With information on drug resistance, regimens are recommended to treat infection caused by Helicobacter pylori, a pathogen related to the development of cancer and whose prevalence in the adult population of Latin America is estimated to range between 60 and $70 \%$.

KEY WORDS: National strategy. Antimicrobial resistance. ESKAPE group. Helicobacter pylori.

Correspondencia:

*Silvia Giono-Cerezo

E-mail: sgiono@yahoo.com
Fecha de recepción: 12-11-2019

Fecha de aceptación: 03-01-2020

DOI: 10.24875/GMM.20005624
Gac Med Mex. 2020;156:172-180

Disponible en PubMed

www.gacetamedicademexico.com

0016-3813/৫ 2020 Academia Nacional de Medicina de México, A.C. Publicado por Permanyer. Este es un artículo open access bajo la licencia CC BY-NC-ND (http://creativecommons.org/licenses/by-nc-nd/4.0/). 


\section{Introducción}

La resistencia antimicrobiana se define como la capacidad de un microorganismo para resistir los efectos de los antibióticos; es una característica inherente de la bacteria o puede ser una capacidad adquirida durante el proceso infeccioso.

Según la Organización de las Naciones Unidas (ONU), la resistencia bacteriana es una de las principales amenazas de salud, ya que pone en peligro prioridades globales como el desarrollo humano. En vista de las profundas implicaciones en las actividades económicas, la alimentación, el turismo y las corrientes migratorias, a partir de esta redefinición se han instaurado mecanismos de cooperación, consulta y vigilancia con mayor o menor apoyo de cada país.

Existen tres tipos de infecciones a partir de la resistencia de las bacterias que las causan:

- Infecciones por Enterobacteriaceae, por su impacto en la morbilidad y mortalidad.

- Infecciones por Acinetobacter spp. Informes en varios hospitales revelan que hay opciones terapéuticas limitadas con los antibióticos disponibles. Los antibióticos generados en los últimos años tampoco tienen actividad contra las cepas resistentes a múltiples fármacos (MDR, multidrug-resistant), extremadamente resistentes a fármacos (XDR, extensively drug resistant) o resistentes a todos los antibióticos (PDR, pandrug resistant).

- Otras infecciones graves, como las ocasionadas por Pseudomonas aeruginosa, que pueden ocasionar mortalidad elevada.

El lema de la Organización Mundial de la Salud (OMS) respecto a la resistencia a los antimicrobianos es "ninguna acción hoy, ninguna cura mañana", ya que se estima que la resistencia bacteriana ocasionará 10 millones de muertes por año para el 2050 y una reducción de 2 y $5 \%$ del producto interno bruto en algunos países. Con base en su informe de riesgos, durante el Foro Económico Mundial de 2013 se situó este problema de salud a la par de la proliferación de armas de destrucción masiva y la crisis económica mundial. ${ }^{1}$

Los 17 objetivos de desarrollo sostenible de la agenda para 2030 de la ONU son una llamada a la acción a todos los países para erradicar la pobreza y proteger el planeta, así como para garantizar la paz y la prosperidad; siete de esos objetivos tienen que ver con resistencia antimicrobiana. ${ }^{2}$

En el Plan de Acción Global 2015 se estableció el Sistema Global de Vigilancia, en el que hubo una resolución por parte del grupo de asambleístas de la OMS sobre resistencia antimicrobiana, con la idea de que en la $72^{a}$. Asamblea Mundial de la Salud, en mayo de 2019, se presentaran los avances de los países; infortunadamente, ni el secretario ni el subsecretario de salud de México pudieron acudir para presentar los avances del país. ${ }^{3}$

En el Plan de Acción Global existen cinco objetivos relacionados con el fortalecimiento del conocimiento basado en estudios de vigilancia e investigación.

Respecto a las acciones globales, los países tienen metodologías diferentes para abordar los problemas. Un caso ejemplar es el de Estados Unidos, país que se ha sumado al Global Antimicrobial Resistance Surveillance System (GLASS), que se refiere al uso de estándares de vigilancia con los que se pretende mejorar la seguridad del paciente. Destaca la necesidad de garantizar la calidad de los datos y estandarizar los reportes sobre bacterias resistentes. ${ }^{4}$

En Estados Unidos, los Centros para el Control y la Prevención de Enfermedades (CDC, Centers for Disease Control and Prevention) analizan las infecciones asociadas a la atención de la salud (IAAS) mediante una red nacional que cuenta con más de 24 mil instalaciones de salud, así como más de 63 mil usuarios individuales, lo que da certidumbre sobre la calidad de los datos que se generan. ${ }^{5}$

La OMS recopila y analiza los datos sobre resistencia antimicrobiana y los agrega a la información relativa a los países siguiendo definiciones estándar; en 2011, dedicó el Día Mundial de la Salud a la lucha contra la resistencia antimicrobiana; en 2015, recomendó que los países miembros desarrollaran un plan nacional de combate contra la resistencia antimicrobiana; en 2017 emitió el Programa de Vigilancia Global de la Resistencia Antimicrobiana.

En 2017, en México se anunció la Estrategia Nacional de Acción contra la Resistencia Antimicrobiana, publicada como Plan de acción contra la resistencia a los antimicrobianos para México, cuyo grupo de trabajo incluye a la Secretaría de Educación Pública, Secretaría de Salud, Secretaría de Agricultura y Desarrollo Rural, Secretaría del Medio Ambiente y Recursos Naturales, Secretaría de Economía, Secretaría de Hacienda y Crédito Público, Secretaría de Relaciones Exteriores, Instituto Mexicano del Seguro Social e Instituto de 
Seguridad y Servicios Sociales de los Trabajadores del Estado, bajo la coordinación de la Comisión Federal para la Protección contra Riesgos Sanitarios. Con esta estrategia multisectorial se alinean la vigilancia epidemiológica y sanitaria, el uso de antimicrobianos en salud humana y la investigación. ${ }^{6}$

El 5 de junio de 2018, en el Diario Oficial de la Federación se publicó un acuerdo en el que se declaró la obligatoriedad de la Estrategia Nacional de Acción contra la Resistencia Antimicrobiana por parte de todas las instituciones que integran el Sistema Nacional de Salud?

\section{Las redes regionales de resistencia bacteriana}

La investigación sobre resistencia microbiana a los antibióticos se realiza en redes interdisciplinarias de laboratorios y en asociaciones de investigación nacionales, regionales e internacionales. Los enfoques interdisciplinarios suelen ser útiles, incluso indispensables, para la investigación exitosa de problemas complejos como la resistencia bacteriana. Las redes generan información relativa a los sujetos afectados, en qué hospitales, con que magnitud y extensión, qué tipos de antibióticos se emplean, impacto en la mortalidad, gravedad de la enfermedad e impacto económico, entre otros datos. La mejor definición es que las redes de vigilancia de resistencia microbiana favorecen mejores acciones para la prevención y control.

\section{Red Latinoamericana de Vigilancia de la Resistencia a los Antimicrobianos (ReLAVRA)}

La Red Latinoamericana de Vigilancia de la Resistencia a los Antimicrobianos (ReLAVRA), creada en 1996 con apoyo de la Organización Panamericana de la Salud, tiene la misión de obtener datos microbiológicos confiables, oportunos y reproducibles para ser usados en el mejoramiento de la atención del paciente mediante la instauración de programas sostenibles de garantía de calidad. ${ }^{8}$

La primera red en México fue la de la Asociación Mexicana de Infectología y Microbiología Clínica, que funcionó de 1997 a 2000 y que trabajó en un sistema de calidad de laboratorios para el estudio de bacterias grampositivas y negativas. Por su parte, la Universidad Nacional Autónoma de México, a través del Programa Universitario de Investigación en Salud, instauró el Plan Universitario de Control de la Resistencia Antimicrobiana. ${ }^{9}$
La Red Temática de Investigación y Vigilancia de la Farmacorresistencia es tal vez la más ambiciosa y productiva, ya que incluye 50 hospitales en 20 estados diferentes. . $^{10,11}$

La ReLAVRA incluye cuatro países: Argentina, Brasil, México y España; del último participan la Universidad de Madrid y la Universidad Complutense. Esta red de investigación permite el intercambio de conocimientos y aprendizaje entre estudiantes de posgrado e investigadores.

El reducido número de redes especializadas en patologías específicas y con indicadores obtenidos a partir de la comparación de infecciones comunitarias versus IAAS y otros blancos limita la construcción de denominadores para conocer el impacto real de la resistencia a los antimicrobianos. La OMS y la Organización Panamericana de la Salud han realizado un esfuerzo en la región de las Américas para definir directrices y convocar a los países miembros a desarrollar planes de vigilancia. Las directrices indican elementos básicos para implementar y adaptar redes de vigilancia según las capacidades y desarrollo de la región (GLASS). ${ }^{4}$

En México, los programas nacionales de vigilancia de resistencia antimicrobiana deben transitar de ser enunciativos a evolutivos y garantizar la calidad de la información, la cual debe ser pública y transparente para guiar adecuadamente las acciones en los ámbitos local y regional y ser accesible para las instancias internacionales.

\section{Recomendaciones de la OMS en torno a la resistencia antimicrobiana en IAAS}

Se han registrado 700 mil casos de resistencia antimicrobiana, más que los de cáncer, cólera, diabetes y diarrea. Debido a su impacto, la resistencia antimicrobiana requiere una inversión de 2 a $3.5 \%$ del producto interno bruto; de no llevarse a cabo para el 2050, se calcula que habrá más de 10 millones de muertes por año.

La resistencia antimicrobiana puede originarse por dos mecanismos:

- Selección artificial debida a inadecuado tratamiento antibiótico, en la que se seleccionan clonas resistentes.

- Selección natural, referente a la transferencia horizontal de genes, en la que hay una adquisición de plásmidos con genes de resistencia y así aumenta la prevalencia de bacterias resistentes. ${ }^{12}$ 
En Estados Unidos, los CDC señalan la necesidad de prevenir y detectar tempranamente la resistencia bacteriana. La identificación, control, monitoreo y vigilancia son las únicas acciones que pueden ayudar a prevenir la diseminación de la resistencia antimicrobiana.

Si bien se tienen ejemplos de cómo se propaga la resistencia antimicrobiana en el ambiente, en la comunidad y en los hospitales, es necesario profundizar la investigación en cada uno de estos ámbitos, así como manejar y conocer lo que está pasando en esos niveles. ${ }^{13}$

Los reportes indican que hay resistencia antimicrobiana a los nuevos antibióticos que salen al mercado, un ejemplo entre tantos es el linezolid, que comenzó a comercializarse en 2000 y para el 2001 ya había reportes de resistencia. ${ }^{14}$

En 2017, la OMS promovió la investigación y el desarrollo de antibióticos que han dejado de producirse por la industria farmacéutica, además señaló que hay microorganismos con prioridades críticas porque causan infecciones con elevada morbilidad y mortalidad, como Acinetobacter baumannii, Pseudomonas aeruginosa, Enterococcus, Helicobacter pylori, Salmonella, Campylobacter y Neisseria gonorrhoeae (responsable de infección de transmisión sexual resistente a las cefalosporinas y fluoroquinolonas). En la categoría de prioridad media quedó Streptococcus pneumoniae, para el cual es necesario determinar su perfil de resistencia, además de Hemophilus influenzae y Shigella.

Una sugerencia consiste en estratificar a las bacterias como MDR, XDR y PDR, igual que se hace para Mycobacterium tuberculosis, en virtud de que cada vez son más los reportes de cepas con estas características.

La OMS propone un plan de acción basado en la concientización acerca del problema, el reforzamiento de los conocimientos y la reducción de la incidencia de las infecciones mediante medidas preventivas como el saneamiento ambiental, el lavado de manos y el empleo óptimo de los antimicrobianos, tanto en los humanos como en los animales. ${ }^{5}$ El plan de acción incluye mejorar el conocimiento y la comprensión de la resistencia antimicrobiana en los ámbitos locales y nacionales, la vigilancia de su incidencia, la optimización del grupo de antibióticos y el desarrollo de medidas de contención. El conocimiento sobre la farmacodinamia y farmacocinética de estos antimicrobianos, los mecanismos de acción del antibiótico, de resistencia antimicrobiana y de transmisión, así como la evaluación de la magnitud de la prevalencia depende de los microbiólogos y médicos.
El microbiólogo puede colaborar en la capacitación del personal de salud y hacer campañas de concientización y la comprensión del problema, participando en la educación de pregrado, así como fortalecer el conocimiento mediante la vigilancia y la investigación. En el laboratorio puede investigar los mecanismos de resistencia, detectar, confirmar y medir el impacto de la resistencia antimicrobiana, así como proveer sus conocimientos microbiológicos, para con ello apoyar al médico en la elaboración de guías de tratamiento basadas en estudios epidemiológicos locales en seres humanos, animales y medioambiente. ${ }^{15}$

Los usuarios de la información deben conocer las distintas estrategias, las cuales consisten en:

- Fortalecer el conocimiento para hacer un buen uso de la información, tanto en el ámbito local como en el nacional.

- Medir la tendencia regional de la resistencia antimicrobiana.

- Priorizar las estrategias y formular un consenso y recomendaciones globales.

- Determinar los componentes del sistema de vigilancia y tipo de muestras que llegan a los laboratorios.

- Caracterizar el perfil de sensibilidad antimicrobiana, ${ }^{6}$ con protocolos y controles de calidad internos y externos.

- Presentar informes y asegurarse de que sean aceptados y aplicados en los hospitales o en la comunidad, según corresponda.

Muchas de estas medidas ya están normadas, por ejemplo, las pruebas de sensibilidad de antibióticos se realizan en los laboratorios de acuerdo con el Clinical and Laboratory Standards Institute (CLSI), que anualmente actualiza sus estándares y guías.

Hay niveles de vigilancia que se pueden priorizar y pueden servir para saber cuál es el tratamiento empírico, cuándo aplicar programas hospitalarios o individuales (si los hay) respecto al uso de antibióticos y cómo llevar a cabo el control de infecciones.

La ReLAVRA apoya los criterios de la OMS para determinar qué sucede en cada país de la región. Para la reducción de la incidencia de infecciones se recomiendan medidas efectivas de higiene y de prevención y control, como la higiene de manos efectiva, los procedimientos de limpieza, la reducción de infecciones asociadas a los cuidados de la salud, la vacunación, el saneamiento ambiental; respecto a la salud de los animales, de igual manera se indica la bioseguridad e higiene y la producción animal sustentable. 
En lo anterior, los microbiólogos pueden colaborar con el manejo adecuado de las muestras clínicas y su identificación, con la realización de cultivos adecuados y pruebas de sensibilidad precisas y oportunas, con la vigilancia de los pacientes y del medio ambiente, cuando se requiera. Respecto a la detección temprana de eventos que pueden transformarse en brotes en hospitales y en la comunidad, pueden colaborar con los datos microbiológicos, la caracterización de los brotes, la evaluación de la diseminación de patógenos nosocomiales y en la comunidad, la evaluación del impacto de las estrategias de prevención (vacunas) y el alertamiento al personal de salud sobre la aparición de resistencia a antimicrobianos de patógenos ya en vigilancia o de patógenos emergentes. $^{8}$

La Red debe insistir en el mejor uso de los antimicrobianos, en el diagnóstico oportuno y adecuado y en el reporte acorde con el sitio de la infección, con pruebas especiales de vigilancia, así como en el resguardo de las cepas.

El CLSI formuló algunas pruebas rápidas, complementarias y confirmatorias que pueden ayudar a orientar al médico en cuanto a la valoración o los tratamientos alternativos.

La diseminación global de enterobacterias resistentes a carbapenémicos se inició en Carolina del Norte, de ahí pasó a Nueva York, Israel y Europa; las productoras de carbapenemasas de tipo New Delhi metalobetalactamasa (NDM) surgieron en la India y de ahí se diseminaron a varios países. ${ }^{16}$

En la población animal (peces, aves de granja y mascotas) hacen falta estudios para evaluar la resistencia en el medioambienta. ${ }^{17}$

Para cumplir con el Plan de Acción Mundial de Resistencia Antimicrobiana es necesario asegurar la sostenibilidad de la evaluación mediante la investigación, para lo cual se requiere inversión y el establecimiento de procedimientos, así como aceptar el papel del laboratorio, lo que repercutirá en beneficio del paciente.

\section{El grupo ESKAPE en México}

La resistencia antimicrobiana es un problema de salud pública en todo el mundo relacionada con el uso humano y no humano de antimicrobianos; es uno de los temas tratados en el enfoque multisectorial denominado Una Salud, que conjunta a la OMS, la Organización de las Naciones Unidas para la
Alimentación y la Agricultura y la Organización Mundial de Sanidad Animal. ${ }^{18}$

En la actualidad, las infecciones más graves que amenazan la vida humana son causadas por un grupo de bacterias resistentes a los antibióticos, que la Sociedad Americana de Enfermedades Infecciosas ha nombrado grupo ESKAPE. ESKAPE es una sigla formada con las letras iniciales de los nombres de seis bacterias que ocasionan enfermedades infecciosas graves y cuyos mecanismos de patogenicidad y resistencia antimicrobiana son evolutivamente muy desarrollados..$^{19}$ Las bacterias del grupo ESKAPE son una amenaza crítica de salud porque causan un porcentaje sustancial de IAAS en el hospital moderno (los CDC indican que son responsables de dos terceras partes de las IAAS), representan la mayoría de Ios aislamientos cuya resistencia a los antibióticos es grave y son paradigmas de patogénesis, transmisión y resistencia, por lo que llevan al médico a dilemas terapéuticos.

Las bacterias del grupo ESKAPE son las siguientes:

1. Enterococcus faecium resistente a vancomicina ha surgido como un patógeno nosocomial causante de infecciones del tracto urinario, heridas y del torrente sanguíneo, además se ha relacionado con infecciones derivadas del uso de catéteres y la realización de procedimientos quirúrgicos.

2. Staphylococcus aureus forma parte de la microbiota de la piel y zonas húmedas del cuerpo humano. En portadores mexicanos se han identificado cepas con susceptibilidad antimicrobiana variable. Respecto a las IAAS, $S$. aureus se ha asociado a bacteriemia, infección de herida quirúrgica, endocarditis, artritis piógena, osteomielitis, infecciones de piel y tejidos blandos. Estos aislamientos presentan resistencia a los antibióticos betalactámicos, incluida la meticilina, en cuyo caso se denomina MRSA (methicillin resistant Staphylococcus aureus).

3. Klebsiella pneumonae es una enterobacteria que representa un nivel de amenaza urgente; causa infecciones respiratorias, urinarias y en torrente sanguíneo, adquiridas tanto en hospitales como en la comunidad. En hospitales, donde pueden diseminarse y provocar brotes, se han aislado cepas productoras de betalactamasas de espectro extendido (BLEE) que incluyen a las carbapenemasas.

4. Acinetobacter baumannii se reconoce actualmente como un patógeno causal de infecciones en pacientes de la unidad de cuidados intensivos; provoca neumonías y bacteriemias asociadas al 
uso de catéteres. En la actualidad, la mayoría de los aislamientos muestra multirresistencia incluso a los carbapenémicos.

5. Pseudomonas aeruginosa es un oportunista nosocomial causante de neumonía, bacteriemia, infecciones del tracto urinario y de heridas quirúrgicas, que también se encuentra en el medio ambiente. El número de infecciones causadas por esta bacteria ha aumentado y la mayoría es MDR.

6. Enterobacter cloacae es un bacilo presente en el tracto digestivo. Se ha relacionado con infecciones del tracto urinario, de herida quirúrgica y bacteriemia, pero con mayor frecuencia se ha identificado en pacientes inmunocomprometidos que se encuentran hospitalizados. Debido a la baja permeabilidad de su membrana externa, las enterobacterias presentan resistencia a penicilina, oxazoil penicilina, clindamicina, lincomicinas, glucopéptidos (vancomicina y teicoplanina) y macrólidos.

El primer estudio de vigilancia de bacterias del grupo ESKAPE en México fue publicado en 2012 y fue realizado durante un año en la Unidad de Cuidados Intensivos del Hospital Universitario en Monterrey, Nuevo León. Se analizaron 1693 patógenos de diferentes muestras clínicas; se encontró que las bacterias del grupo ESKAPE representaban $64 \%$ de los aislamientos. En primer lugar, se encontró $A$. baumannii y, en segundo, $P$. aeruginosa. ${ }^{20} P$. aeruginosa y A. baumannii fueron MDR, incluso a los carbapenémicos; $20 \%$ de los aislamientos de $A$. baumannii fueron PDR; $36 \%$ de los aislamientos de K. pneumoniae MDR fueron productores de BLEE. Las infecciones resultaron con escasas opciones de tratamiento antimicrobiano. Respecto a las bacterias grampositivas, $62 \%$ de los aislamientos de $S$. aureus presentaron resistencia a meticilina y $4 \%$ a vancomicina; en cuanto a Enterococcus spp, se observó que $10 \%$ fue resistente a vancomicina.

El segundo trabajo publicado en México se realizó en el Instituto Nacional de Cancerología. ${ }^{21}$ Se analizaron las bacterias del grupo ESKAPE aisladas de hemocultivos de pacientes con cáncer. Se revisaron más de 33 mil hemocultivos obtenidos durante un periodo de 10 años. Se observó que $17 \%$ de los hemocultivos tenían aislamiento bacteriano, $92 \%$ de estos fueron MDR y $58 \%$ fueron bacilos gramnegativos; $6 \%$ fue $K$. pneumoniae, productor de BLEE en $11 \% ; 6 \%$ fue $P$. aeruginosa, del cual $11 \%$ fue MDR. Se encontró E. cloacae con porcentaje elevado de producción de BLEE, así como $A$. baumannii con $24 \%$ de MDR. Los grampositivos presentaron $37 \%$ de MDR, $9 \%$ fue S. aureus, $21 \%$ fue resistente a meticilina, $2 \%$ fue Enterococcus spp. y $32 \%$ resistente a vancomicina. Los investigadores concluyeron que las cepas del grupo ESKAPE MDR fueron las que se aislaron más frecuentemente en pacientes con neoplasias hematológicas. ${ }^{21}$

El tercer informe fue publicado por el Programa Universitario de Investigación en Salud de la Universidad Nacional Autónoma de México; en él se evidencia el estado actual de la resistencia antimicrobiana en México. Se incluyeron 11900 aislamientos obtenidos durante 2016 y 2017, provenientes de 14 hospitales de seis estados de la República Mexicana. Se observó que la mayoría de los aislamientos (73 \%) provenía de urocultivos, en $91 \%$ se identificó Escherichia coli y en $8.5 \%$, K. pneumoniae; $27 \%$ de los aislamientos se obtuvo de hemocultivos. Las bacterias gramnegativas fueron E. coli, K. pneumoniae, E. cloacae, $P$. aeruginosa y $A$. baumannii. K. pneumoniae y $E$. cloacae presentaron resistencia a todas las cefalosporinas y $60 \%$ de los aislamientos fueron productores de BLEE, lo cual evidencia la urgencia de intervenciones para controlar el problema de la resistencia antimicrobiana. Los aislamientos grampositivos estudiados fueron únicamente $S$. aureus, que representaron $21 \%{ }^{9}$

El trabajo más reciente fue publicado en marzo del 2019, en el que participaron 47 hospitales de 20 estados de México. Se estudiaron 22943 aislamientos obtenidos de enero a junio de 2018, en los que se encontró un alto porcentaje de bacterias gramnegativas resistentes a carbapenemasas: más de $50 \%$ de A. baumannii, $40 \%$ de $P$. aeruginosa y $12 \%$ de Klebsiella spp. y E. cloacae. La MDR fue muy elevada en $A$. baumannii (53 \%) y K. pneumoniae (22\%). En el grupo de las bacterias grampositivas, $21 \%$ fue $S$. aureus resistente a meticilina y $21 \%$ fue enterococos resistentes a vancomicina. ${ }^{10}$

En resumen, las principales bacterias del grupo ESKAPE que causan infecciones nosocomiales en México fueron Klebsiella spp. MDR productora de BLEE, Enterobacter spp. productor de BLEE, A. baumannii y $P$. aeruginosa MDR (incluso resistente a los carbapenémicos), $S$. aureus resistente a meticilina y $E$. faecium resistente a vancomicina.

En los últimos años, en México se incrementaron las infecciones por bacterias del grupo ESKAPE, la mayoría en unidades de cuidados intensivos; los aislamientos se han caracterizado como MDR. A. baumannii MDR y K. pneumoniae MDR requieren atención inmediata, así como las cepas MRSA y E. faecium 
resistente a vancomicina. Es importante considerar que estos aislamientos son el punto de partida para brotes de infecciones asociadas con bacteriemias graves asociadas al cuidado de la salud.

Finalmente es necesario actualizar y maximizar el uso de tratamientos antimicrobianos, con el objetivo de preservar su utilidad. La información de los estudios realizados en México señala la urgencia de la implementación de medidas para el control de la resistencia antimicrobiana. Si no actuamos hoy, no habrá cura mañana.

\section{Los antibióticos pueden prevenir el cáncer gástrico por Helicobacter pylori}

El cáncer gástrico es la segunda causa de mortalidad debida a tumores en el mundo. Particularmente en países en desarrollo, el éxito del tratamiento depende de un diagnóstico temprano; infortunadamente este cáncer alerta demasiado tarde al paciente sobre acudir al médico. ${ }^{22}$

El Global Cancer Observatory (GCO) señala áreas donde las tasas de cáncer gástrico son más altas, como Asia y Latinoamérica. En México se calcula que tan solo durante el primer año de atención médica se erogan aproximadamente 2 mil millones de pesos en costos directos relacionados con el cáncer gástrico y el cáncer de mama. La OMS estima que el número de pacientes afectados por estas neoplasias se duplicará para el 2020. ${ }^{23}$

El principal factor de riesgo para este cáncer es la épsilon protobacteria Helicobacter pylori, la cual posee una habilidad extraordinaria para colonizar el estómago de los pacientes; si bien en la mayoría de los casos la infección es asintomática, en algunos es causa de úlcera péptica y, en el peor de los casos, de cáncer gástrico. El descubrimiento de que una infección fuera factor de riesgo de cáncer ha derivado en cambios importantes en el manejo de la medicina moderna.

La prevalencia global de infección por $H$. pylori sigue siendo alta, aunque está disminuyendo en muchas regiones del mundo, sin embargo, en Asia y Latinoamérica se estima que de 60 a $70 \%$ de los adultos portan este patógeno. ${ }^{24}$

En México se hizo un estudio de seroprevalencia con más de 11 mil sueros de pacientes representativos de todas las edades y de todos los estados de la República Mexicana. Se encontró que la infección empieza en los primeros años de vida, como ocurre en los países en desarrollo, y después de los 20 años más de $70 \%$ de los adultos están infectados y permanecen con tasas de infección elevadas a lo largo de su vida. ${ }^{24}$

La reconstrucción de la historia natural de $H$. pylori indica que durante la niñez este patógeno coloniza la mucosa gástrica, donde establece una señalización hacia el epitelio, el cual responde con inflamación que produce gastritis, que en la mayoría de los casos se establece como crónica y puede permanecer asintomática durante toda la vida. Sin embargo, la inflamación exagerada de la mucosa gástrica que puede llevar a atrofia cuando la bacteria tiene genes de virulencia y el epitelio muestra mayor sensibilidad a la respuesta inflamatoria. Si la inflamación y la bacteria que la provoca permanecen, pueden desarrollarse lesiones preneoplásicas que con el tiempo evolucionarán a cáncer gástrico.

Se ha identificado evidencia sólida de que la infección puede tener un efecto benéfico en los primeros años de vida: estudios epidemiológicos muestran una asociación inversa entre la infección por $H$. pylori y adenocarcinoma del esófago; al parecer, cuando la bacteria está en el estómago funciona como un amortiguador biológico que evita el reflujo y el constante contacto con el ácido del esófago, que al final lleva a adenocarcinoma. ${ }^{25}$

También se ha encontrado que la infección por H. pylori está asociada a reducción en el riesgo de asma y alergia, por lo que se está estudiando esta relación con otras enfermedades autoinmunes. En Alemania, en modelos de ratones recién nacidos se demostró que la interleucina 18 producida por las células dendríticas estimula y diferencia las células T reguladoras que inhiben las respuestas autoinmunes. Al parecer, Helicobacter pylori estimula las células $T$ reguladoras en el estómago durante la niñez y coadyuva a evitar enfermedades autoinmunes Debido a las observaciones anteriores no se tiene la seguridad de que deba erradicarse la infección por $H$. pylori, ya que hay indicios de que esta bacteria forma parte de la microbiota del estómago y tiene funciones fisiológicas benéficas, por lo que durante los primeros años de la infección no hay mayor afectación. ${ }^{26}$ Las lesiones precancerosas empiezan después de los 40 años, por lo que se tiene que actuar antes de que se manifiesten para prevenir el desarrollo del cáncer gástrico.

\section{Recomendaciones en el tratamiento de H. pylori resistente a los antimicrobianos}

Las recomendaciones internacionales se basan principalmente en estudios realizados en Europa y China; 
las investigaciones en Estados Unidos son escasas y en Canadá no se cuenta con información confiable en torno a la resistencia de esta bacteria. ${ }^{27,28}$

En México se han efectuado ensayos clínicos con diferentes esquemas terapéuticos. La terapia estándar triple fue probada en varios miles de pacientes de siete lugares de América Latina: México (Sonora y Chiapas), Honduras, Nicaragua, Costa Rica, Colombia y Chile. En las poblaciones en las que se erradicó la infección, el tratamiento por 14 días fue el más efectivo y con resultados completamente diferentes a los observados en China y Europa. De ahí la importancia de los estudios regionales, locales y nacionales, para conocer la verdadera eficacia de los tratamientos en las diferentes poblaciones. ${ }^{29}$

Tomando en cuenta la investigación anterior y otras que ha realizado la Red Latinoamericana de Vigilancia de la Resistencia a los Antimicrobianos, en el consenso latinoamericano de 2014 se recomienda la terapia estándar triple por 14 días como primera opción y como segunda, la combinación de omeprazol, amoxicilina y claritromicina, en la que la resistencia a la claritromicina define la utilidad del tratamiento. ${ }^{30}$

En México se ha estudiado la resistencia de Helicobacter pylori a los antimicrobianos desde hace aproximadamente 20 años. Cuando se hizo el consenso europeo estaba por debajo de $5 \%$ y la resistencia específica a la claritromicina era de $12 \%$, si bien este antibiótico todavía tenía utilidad clínica; la resistencia al metrodinazol era de $40 \%$, si bien con variaciones; en los diferentes periodos estudiados se encontró $7 \%$ de resistencia a amoxicilina. En la última colección de cepas de 2017 se registró $60 \%$ de resistencia a metrodinazol y la resistencia a claritromicina fue relevante. ${ }^{31}$

En 2018, en trabajo conjunto con la Asociación Mexicana de Gastroenterología se elaboró el IV Consenso Mexicano sobre Helicobacter pylori, en el que como primera línea de tratamiento en regiones con tasas elevadas de resistencia dual (claritromicina y metronidazol) se recomienda el esquema cuádruple durante 14 días, pudiendo considerar dos opciones: ${ }^{31}$

- Terapia cuádruple con sales de bismuto: inhibidor de la bomba de protones, subcitrato de bismuto, tetraciclina y metronidazol.

- Terapia cuádruple sin bismuto (terapia concomitante): subcitrato de bismuto, amoxicilina, claritromicina y metronidazol.

En 2014, la OMS convocó a expertos en Helicobacter pylori para elaborar recomendaciones dirigidas a los países donde el cáncer gástrico es un problema serio. Existe una propuesta de tamizaje mínimo para identificar a candidatos para el esquema de erradicación de la bacteria, ${ }^{32}$ en la cual se indica que en un país se pueden detectar poblaciones de alto riesgo y seleccionar grupos por edad. Por ejemplo: en México, las tasas de mortalidad más altas por cáncer gástrico se observan en Yucatán, Chiapas, Zacatecas y Baja California, estados en donde sería importante concentrar la atención.

Las infecciones por Helicobacter pylori siguen siendo frecuentes en adultos mexicanos; $3 \%$ de ellas evolucionan a cáncer gástrico, con alta tasa de mortalidad y muy altos costos para el sistema de salud. El consenso mexicano actual ha corregido el esquema terapéutico de primera opción y se espera que la erradicación de la infección en adultos mayores de 40 años sin lesiones preneoplásicas sea una medida eficaz para prevenir el desarrollo de cáncer gástrico, sin embargo, es algo que aún debe probarse. ${ }^{30}$

\section{Bibliografía}

1. World Health Organization. World Health Day. Suiza: WHO; 2011

2. World Health Organization. La resistencia a los antimicrobianos. Suiza: WHO; 2019.

3. World Health Organization. Farmacorresistencia. Suiza: WHO; 2015.

4. World Health Organization. Drug resistance. Suiza: WHO; 2015.

5. Centers for Disease Control and Prevention. National Healthcare Safety Network. EE. UU.: CDC; 2019.

6. Mussaret BZ, Dreser A, Figueroa IM. A collaborative initiative for the containment of antimicrobial resistece in Mexico. Zooneses Public Health. 2015;62:52-57.

7. Acuerdo por el que se declara la obligatoriedad de la Estrategia Nacional de Acción contra la Resistencia a los Antimicrobianos. México: Diario Oficial de la Federación; 2018 Jun 5.

8. Red Latinoamericana de Vigilancia de la Resistencia a los Antimicrobianos (ReLAVRA). EE. UU.: Organización Panamericana de la Salud; 2019.

9. Universidad Nacional Autónoma de México. Plan Universitario de Control de la Resistencia Antimicrobiana. México: UNAM; 2018.

10. Garza-González E, Morfín-Otero R, Mendoza-Olazarán S, Bocanegra-lbarias P, Flores-Treviño S, Rodríguez-Noriega E, et al. A snapshot of antimicrobial resistance in Mexico. Results from 47 centers from 20 states during a six-month period. PLoS One. 2019;14:e0209865.

11. Universidad de Colima [sitio web]. Red Temática de Investigación y Vigilancia de la Farmacorresistencia. México: Universidad de Colima. [Actualización: 2019].

12. O'Neill CB. The review on antimicrobial resistence. Suiza: World Intellectual Property Organization; 2016.

13. Centers for Disease Control and Prevention. Vital signs. EE. UU.: CDC; 2018.

14. Walsh CT, Wencewicz TA. Prospects for new antibiotics: a molecule-centeres perspective. J Antibiot (Tokyo). 2014;67:7-22.

15. World Health Organization. Resistencia a los antimicrobianos. Suiza: WHO; 2016

16. Codjoe FS, Donkor ES. Carbapenem resistance: a review. Med Sci. 2017;6:1-21.

17. Köck R, Daniels-Haardt I, Becker K, Mellman A, Friedrich A, Mevius D, et al. Carbapenem-resistant Enterobacteriaceae in wildlife, food-producing, and companion animals: a systematic review. Clin Microbiol Infect. 2018;24:1241-1250.

18. Wernli D, Jørgensen PS, Harbarth S, Carroll SP, Laxminarayan R, Levrat N, et al. Antimicrobial resistance: the complex challenge of measurement to inform policy and the public. PLoS Med. 2017;14:e1002378.

19. Santajit S, Idrawattana N. Mechanisms of antimicrobial resistance in ESKAPE pathogens. BioMed Res Int. 2016;2475067:2016. 
20. Llaca-Díaz JM, Mendoza-Olazarán S, Camacho-Ortiz A, Flores S, Garza-González E. One-year surveillance of ESKAPE pathogens in an Intensive Care Unit of Monterrey, Mexico. Chemotherapy. 2012;58:475-481.

21. Velázquez-Acosta $C$, Cornejo-Juárez $P$, Volkow-Fernández P. Cepas E-ESKAPE multidrogorresistentes aisladas en hemocultivos de pacientes con cáncer. Salud Publica Mex. 2015;60:151-157.

22. Yoon $\mathrm{H}$, Kim N. Diagnosis and management of high risk group for gastric cancer. Gut and Liver. 2015:9:5-17.

23. Ferlay J, Colombet M, Bray F. Cancer Incidence in five continents. Francia: International Agency for Research on Cancer; 2019.

24. Rawla P, Barsouk A. Epidemiology of gastric cancer: global trends, risk actors and prevention. Prz Gastroenterol. 2019:14:26-38.

25. Román-Román A, Martínez-Carrillo DN, Atrisco-Morales J, Azúcar-Heziquio JC, Cuevas-Caballero AS, Castañón-Sánchez CA, et al. Helicobacter pylori vacA s1m1 genotype but not cagA or babA2 increase the risk of ulcer and gastric cancer in patients from Southern Mexico. Gut Pathog. 2017;9:18.

26. Burkitt MD, Duckworth CA, Williams JM, Pritchard DM. Helicobacter pylori-induces gastric pathology: insights from in vivo and ex vivo models. Dis Model Mech. 2017;10:89-104.
27. Kariya, S, Okano M, Nishizaki K. An association between Helicobacter pylori and upper respiratory tract disease: fact or fiction? World J Gastroenterol. 2014;20:1470-1484.

28. Hu Y, Zhu Y, Lu NH. Novel and effective therapeutic regimens for Helicobacter pylori in an era of increasing antibiotic resistance. Front Cell Infect Microbiol. 2017;7:168

29. Porras C, Nodora J, Sexton R, Ferreccio C, Jiménez S, Domínguez RL, et al. Epidemiology of Helicobacter pylori infection in six Latin American countries (SWOG Trial S0701). Cancer Causes Control. 2013;24:209-215.

30. Garza-González E, Pérez-Pérez GI, Maldonado-Garza HJ, Bosques-Padilla FJ. A review of Helicobacter pylori diagnosis, treatment, and methods to detect eradication. World J Gastroenterol. 2014:20:1438-1449.

31. Bosques-Padilla FJ, Remes-Troche JM, González-Huezo MS, Pérez-Pérez G, Torres-López J, Abdo-Francis JM, et al. IV Consenso Mexicano sobre Helicobacter pylori. Rev Gastroenterol Mex. 2018; 83(3):325-341.

32. Mascellino MT, Porowska B, de Angelis M, Oliva A. Antibiotic susceptibility, heteroresistance, and updated treatment strategies in Helicobacter pylori infection. Drug Des Devel Ther. 2017;11:2209-2220. 